\title{
Genetic code: the unity of chemism and semiosis
}

\author{
A hypothesis (Synopsis)
}

\author{
Miloje M. Rakočević \\ University of Niš, Faculty of Sciences and Mathematics, Department of Chemistry, \\ Višegradska 33, 18000 Niš, Serbia
}

\begin{abstract}
This synopsis announces a regular paper on the same topic it provides evidence for three hypotheses: The unity of chemism and semiosis within genetic code; Boolean spaces are key determinants of the genetic code, and third: perfect and friendly numbers (as quantities within Boolean spaces) are key determinants of the Genetic code.
\end{abstract}

Key words. Genetic code; amino acids; Boolean spaces; perfect numbers; friendly numbers.

In this Synopsis is the word about three hypotheses: 1. The main hypothesis given in the title; 2. The separate hypothesis which claims that Boolean spaces are key determinants of the genetic code; and 3. The special hypothesis which claims that perfect and friendly numbers are key determinants of the Genetic code, and these numbers are not taken here as arithmetic numbers but as quantities contained in the Boolean spaces.

The unity referred to in the main hypothesis concerns the unity of the corresponding semiotic systems and the corresponding chemical systems and/or arrangements; the unity achieved primarily through mirror symmetry, but also through other forms of symmetry such as "The symmetry in the simplest case" (Marcus, 1989) and the like (Box 1 \& 2; Displays 1-5; Tables 1-5) (Appendix: Tables A1-A5 and Figures A1-A4). In addition to the symmetry, the logic that each new distinction in semiotic system ${ }^{1}$ product a new distinction in the chemical system also appears.

The right side od Display 2 is the same as in Display 1 (20 AAs as two decades), except that the order of amino acids (in the similarity), from the first to the last, is indicated. (Cf. MMR, 2019, Table 2, p. 14.) In other Displays as it is given in their legends. In Displays 4 and 5 (on the right) the order of amino acids is given through quintets: the first with the third, and the second with the fourth.

\footnotetext{
${ }^{1}$ MMR, 2018a, pp. 30-31: "Rumer (1966) suggests that encoding by dinucleotide aggregations is mediated by 'grammatical' formalism (the relation between words and the root of the word), semantics (one-meaning and multy-meaning codon families) and by semiology, i.e. semiotics (the classification of nucleotide doublets after the number of their hydrogen bonds which appear here as 'signifiant' and 'signifié' (signifier and signified) at the same time, that is as their unity (De Saussure, 1985, p. 99)."]
} 
Box 1. Mirror symmetry through the number of atoms as a unity of numerical quantities and chemical qualities (The unity of chemism and semiosis)

\begin{tabular}{|c|c|}
\hline $\begin{array}{l}\text { Start: a unique sequence of Periodic System of Numbers } \\
\text { (PSN) in front of a mirror, with superposition; then "crossing" } \\
\text { with a unique 6-bit binary tree sequence (Box 2): } 010 / 101 \\
\text { as } \underline{2} / \underline{5}(3 \times \underline{2} \text { and } 2 \times \underline{5}) \text { : } \\
00-11-22 \text { / } 22-11-00 \rightarrow \mathbf{0 0 - 1 1 - 2 2 - 1 1 - 0 0} \rightarrow 02,13,24,16,05\end{array}$ & 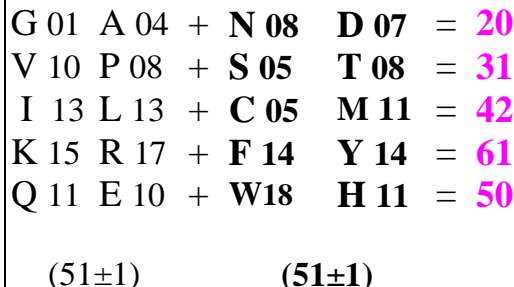 \\
\hline $\begin{array}{l}\text { Then mirroring with the result in Display 1. Arrangem. as in } \\
\text { (MMR, 2019, Fig. 2, p. } 17 \text { and Tab. A3, p. 30; 2021, Fig. 2, p. } 55 \\
\text { and Fig. A2, p. 88). PSN as in (MMR, 2019, Fig. A1, p. 28). }\end{array}$ & $\begin{array}{l}\text { Display 1. The unity of chemism and } \\
\text { semiosis (I) } \\
\underline{\text { arXiv:2108.01563v4 } 4 \text { [q-bio.BM] }}\end{array}$ \\
\hline
\end{tabular}

Display 2. Ordinal number of amino acids according their chemical properties, from the first to the $20^{\text {th }}$ [The unity of chemism and semiosis (II)]

\begin{tabular}{|c|c|c|c|c|c|c|c|c|}
\hline $\begin{array}{l}{ }_{\mathbf{0 1}} \mathrm{G} 10 \\
{ }_{\mathbf{0 3}} \mathrm{V} 19 \\
{ }_{\mathbf{0 5}} \mathrm{I} 22 \\
{ }_{\mathbf{0 7}} \mathrm{K} 24 \\
{ }_{\mathbf{0 9}} \mathrm{Q} 20\end{array}$ & $\begin{array}{l}\text { 02 } \mathrm{A} 13 \\
\mathbf{0 4}^{\mathrm{P}} 17 \\
\mathbf{0 6}^{\mathrm{L}} 22 \\
\text { 08 }^{\mathrm{R}} 26 \\
\text { 10 }^{\mathrm{E}} 19\end{array}$ & $\begin{array}{l}{ }_{11} \mathrm{~N} 17 \\
{ }_{13} \mathrm{~S} 14 \\
{ }_{15} \mathrm{C} 14 \\
{ }_{17} \mathrm{~F} 23 \\
{ }_{19} \mathrm{~W} 27\end{array}$ & $\begin{array}{l}\mathbf{1 2}^{\mathrm{D}} 16 \\
\mathbf{1 4}^{\mathrm{T}} 17 \\
{ }_{\mathbf{1 6}} \mathrm{M} 20 \\
\mathbf{1 8}^{\mathrm{Y} 24} \\
{ }_{20} \mathrm{H} 20\end{array}$ & $\begin{array}{c}56 \\
11 \\
67 \\
11 \\
78 \\
97 \\
11 \\
86\end{array}$ & 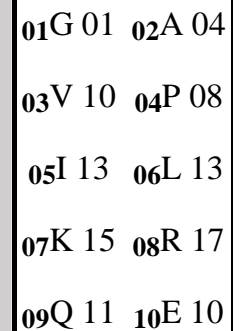 & $\begin{array}{l}{ }_{11} \mathrm{~N} 08 \\
{ }_{13} \mathrm{~S} 05 \\
{ }_{15} \mathrm{C} 05 \\
{ }_{17} \mathrm{~F} 14 \\
{ }_{19} \mathrm{~W} 18\end{array}$ & $\begin{array}{l}\mathbf{1 2}^{\mathrm{D}} 07 \\
\mathbf{1 4}^{\mathrm{T}} 08 \\
\mathbf{1 6}^{\mathrm{M}} 11 \\
\mathbf{1 8} \mathrm{Y} 15 \\
\mathbf{2 0}_{\mathbf{0}} \mathrm{H} 11\end{array}$ & $\begin{array}{c}20 \\
11 \\
31 \\
11 \\
42 \\
61 \\
11 \\
50\end{array}$ \\
\hline & & & & & & & & \\
\hline
\end{tabular}

The number 56 as double perfect number. The 384 as total number of atoms within 20 amino acid molecules $(180+204)$. The pair 220 and 284 as the first friendly numbers. From six permutations: 012, 021, 102, 120, 201, 210, the 102 as a half of 204 atoms; the 210 as the sum of numbers from 1 to 20 ; number 120 as the relational quantity between the second friendly number and the total number of atoms.

\footnotetext{
${ }^{2}$ The paper from the cited reference forms a wholeness with this synopsis which will be the basis for creating a future regular Paper. The quantity $(51 \pm 1)$, in Display 1, we recognize as Gauss' number 51 in the determination of the genetic code (DOI $10.31219 /$ osf.io/bpqzt \& DOI 10.31219/osf.io/suwzn)
} 
Display 3. The arrangement of amino acids as in Display 2 with an innovation on the right side [The unity of chemism and semiosis (III)]

\begin{tabular}{|c|c|c|c|c|c|c|}
\hline $01 \mathrm{G} 10$ & $\mathbf{0 2} \mathrm{A} 13$ & ${ }_{11} \mathrm{~N} 17 \quad{ }_{12} \mathrm{D} 16$ & 56 & $01 \mathrm{G} 1002 \mathrm{~A} 13$ & ${ }_{11} \mathrm{~N} 17 \quad{ }_{12} \mathrm{D} 16$ & 56 \\
\hline $\mathbf{0 3} \mathrm{V} 19$ & ${ }_{04} \mathrm{P} 17$ & ${ }_{13} \mathrm{~S} 14 \quad 14 \mathrm{~T} 17$ & 67 & ${ }_{\mathbf{0 3}} \mathrm{V} 19 \quad \mathbf{0 4}^{\mathrm{P}} \mathrm{P} 17$ & ${ }_{13} \mathrm{~S} 14 \quad 14 \mathrm{~T} 17$ & 67 \\
\hline $05^{\mathrm{I}} 22$ & ${ }_{06} \mathrm{~L} 22$ & ${ }_{15} \mathrm{C} 14 \quad{ }_{16} \mathrm{M} 20$ & 78 & ${ }_{05} \mathrm{I} 22 \quad{ }_{06} \mathrm{~L} 22$ & ${ }_{15} \mathrm{C} 14 \quad{ }_{16} \mathrm{M} 20$ & 78 \\
\hline${ }_{07} \mathrm{~K} 24$ & o8R 26 & ${ }_{17} \mathrm{~F} 23 \quad 18 \mathrm{Y} 24$ & 97 & $\mid 07 \mathrm{~K} 24 \quad 08 \mathrm{R} 26$ & ${ }_{17} \mathrm{~F} 23 \quad 18 \mathrm{Y} 24$ & 97 \\
\hline 09Q 20 & ${ }_{10} \mathrm{E} 19$ & ${ }_{19} \mathrm{~W} 27 \quad 20 \mathrm{H} 20$ & 86 & Q $20 \quad{ }_{10}$ E 19 & ${ }_{19} \mathrm{~W} 27{ }_{20} \mathrm{H} 20$ & 86 \\
\hline \multicolumn{4}{|c|}{ Left: $(56+78+86=220]$} & $01 \mathrm{G} 1002 \mathrm{~A} 13$ & ${ }_{11} \mathrm{~N} 17 \quad{ }_{12} \mathrm{D} 16$ & 56 \\
\hline \multicolumn{7}{|c|}{ Right: $[56+78+86=\mathbf{2 2 0}][67+97+56=\mathbf{2 2 0}]$} \\
\hline \multicolumn{4}{|c|}{ (First perfect 496) (First friendly 220) } & \multicolumn{3}{|c|}{$220+220=440[440+56=496]$} \\
\hline
\end{tabular}

The innovation is that the first row is repeated once more at the bottom (on the right side of Display. In that case the number of atoms in odd rows and even rows is equal and is exactly as much as the first friendly number (220). If the obtained result is increased by twice the value of the second perfect number (28) then the third perfect number (494) is obtained. Display 4 The arrangement of amino acids as in Display 3 with a new innovation on the right side [The unity of chemism and semiosis (IV)]

Display 4 The arrangement of amino acids as in Display 3 with a new innovation [The unity of chemism and semiosis (IV)]

\begin{tabular}{|c|c|c|c|c|c|c|c|}
\hline \multicolumn{3}{|c|}{ Display 1} & \multicolumn{3}{|c|}{$\downarrow$} & \multicolumn{2}{|l|}{1} \\
\hline${ }_{01} \mathrm{G} 01$ & 02 $\mathrm{A} 04$ & ${ }_{11} \mathrm{~N} 08 \quad{ }_{12} \mathrm{D} 07$ & ${ }_{01} \mathrm{G} 01$ & ${ }_{11} \mathrm{~N} 08$ & ${ }_{06} \mathrm{~L} 13$ & ${ }_{16} \mathrm{M} 11$ & 33 \\
\hline $03 \mathrm{~V} 10$ & ${ }_{04} \mathrm{P} 08$ & ${ }_{13} \mathrm{~S} 05 \quad{ }_{14} \mathrm{~T} 08$ & 02A 04 & ${ }_{12} \mathrm{D} 07$ & ${ }_{07} \mathrm{~K} 15$ & ${ }_{17} \mathrm{~F} 14$ & 40 \\
\hline${ }_{05} \mathrm{I} 13$ & ${ }_{06} \mathrm{~L} 13$ & ${ }_{15} \mathrm{C} 05 \quad 16 \mathrm{M} 11$ & ${ }_{03} \mathrm{~V} 10$ & ${ }_{13} \mathrm{~S} 05$ & 08R 17 & $18 \mathrm{Y} 15$ & 47 \\
\hline${ }_{07} \mathrm{~K} 15$ & ${ }_{08} \mathrm{R} 17$ & ${ }_{17} \mathrm{~F} 14 \quad{ }_{18} \mathrm{Y} 15$ & ${ }_{04} \mathrm{P} 08$ & ${ }_{14} \mathrm{~T} 08$ & ${ }_{09} \mathrm{Q} 11$ & ${ }_{19} \mathrm{~W} 18$ & 45 \\
\hline${ }_{09} \mathrm{Q} 11$ & ${ }_{10} \mathrm{E} 10$ & ${ }_{19} \mathrm{~W} 18{ }_{20} \mathrm{H} 11$ & $05 \mathrm{I} 13$ & ${ }_{15} \mathrm{C} 05$ & ${ }_{10} \mathrm{E} 10$ & ${ }_{20} \mathrm{H} 11$ & 39 \\
\hline \multicolumn{8}{|c|}{$\begin{array}{c}(\underline{\mathbf{3}} 3+\underline{\mathbf{3}} 9=72)(\underline{4} 0+45=85)(47=37+10) \\
(33+45=78)(39+40=79)\end{array}$} \\
\hline
\end{tabular}

On the left side the arrangement of AAs is the same as in Display 1 (20 AAs as two decades), except that the order of amino acids (in the similarity), from the first to the last, is indicated here. (Cf. MMR, 2019, Table 2, p. 14.) The AAs decades placed on the right are divided into quintets: the first with the third, and the second with the fourth. Such an arrangement shows the unity of chemism and semiosis in a different way (different from this presented in Box 1), as it is represented in Table 1. Furthermore, Table 4 shows a more complete unity of chemism and semiosis through the chemical properties of molecules, the number of atoms in them, as well as through ordinal number of AAs in the system of chemical similarity of molecules as such. 
Display 5. The arrangement of amino acids as in Display 3 with a new innovation on the right side [The unity of chemism and semiosis $(\mathrm{V})$ ]

\begin{tabular}{|c|c|c|c|c|c|c|c|}
\hline \multicolumn{4}{|c|}{ Display 1) } & \multicolumn{2}{|l|}{$T$} & \multicolumn{2}{|l|}{$\uparrow$} \\
\hline${ }_{01} \mathrm{G} 01$ & 02A 04 & ${ }_{11} \mathrm{~N} 08 \quad{ }_{12} \mathrm{D} 07$ & ${ }_{01} \mathrm{G} 01$ & ${ }_{20} \mathrm{H} 11$ & ${ }_{06} \mathrm{~L} 13$ & ${ }_{15} \mathrm{C} 05$ & 30 \\
\hline $03 \mathrm{~V} 10$ & ${ }_{04} \mathrm{P} 08$ & ${ }_{13} \mathrm{~S} 05 \quad{ }_{14} \mathrm{~T} 08$ & 02 $\mathrm{A} 04$ & ${ }_{19} \mathrm{~W} 18$ & ${ }_{07} \mathrm{~K} 15$ & ${ }_{14}$ T 08 & 55 \\
\hline 05I 13 & 06 $\mathrm{L} 13$ & ${ }_{15} \mathrm{C} 05 \quad{ }_{16} \mathrm{M} 11$ & $03 \mathrm{~V} 10$ & $18 \mathrm{Y} 15$ & ${ }_{08} \mathrm{R} 17$ & ${ }_{13} \mathrm{~S} 05$ & 37 \\
\hline${ }_{07} \mathrm{~K} 15$ & ${ }_{08} \mathrm{R} 17$ & ${ }_{17}$ F $14 \quad \mathbf{1 8}$ Y 15 & ${ }_{\mathbf{0 4}} \mathrm{P} 08$ & ${ }_{17} \mathrm{~F} 14$ & ${ }_{09} \mathrm{Q} 11$ & 12D 07 & 40 \\
\hline${ }_{09} \mathrm{Q} 11$ & ${ }_{10} \mathrm{E} 10$ & ${ }_{19} \mathrm{~W} 18 \quad 20 \mathrm{H} 11$ & ${ }_{05} \mathrm{I} 13$ & ${ }_{16} \mathrm{M} 11$ & ${ }_{10} \mathrm{E} 10$ & ${ }_{11} \mathrm{~N} 08$ & 42 \\
\hline \multicolumn{8}{|c|}{$\begin{array}{c}(30+42=72) \quad(40+55=\mathbf{9 5})(37=47-10) \\
(30+55=\mathbf{8 5})(42+40=82\end{array}$} \\
\hline
\end{tabular}

The difference compared to Display 4 is that the direction of "movement" of the amino acids in the "blue" quintet is vice versa.

Box 2. The determination of the series of the numbers 0-63 on the 6-bit binary tree

$$
\begin{aligned}
& \text { /00 - 07/08 - 15/16 - 23/24 - 31//32 - 39/40 - 47/48 - 55/56 - 63/ } \\
& \begin{array}{lllllllllll}
28 & & 92 & & 156 & \mathbf{2 2 0} & \mathbf{2 8 4} & 348 & 412 & 476
\end{array} \\
& / 00 \text { - 07/00 - 15/00 - 23/00 - 31//00 - 39/00 - 47/00 - 55/00 - 63/ } \\
& \begin{array}{llllllll}
28 & 120 & 276 & 496 & 780 & 1128 & 1540 & 2016
\end{array} \\
& \begin{array}{lllllll}
92 & 156 & \mathbf{2 2 0} & \mathbf{2 8 4} & 348 & 412 & 476
\end{array}
\end{aligned}
$$

"The determination of the series of the numbers 0-63 [on the 6-bit binary tree]. When we look closely into the structure of the sequence $0-63$ of the series of the natural numbers we come to the obvious and self-evident explanation of the reason why the genetic code must be six-bit code, no matter if it is the manifestation in the form of the Gray Code model (Swanson, 1984, p 188), or it is in the form of the Binary tree (Rakočević, 1994, p. 38) [Rakočević, 1998, Fig. 1, p. 284]. There must be 8 codon i.e. amino acid classes. The structure of the sequence $0-63$ is strictly determined by third perfect number (496) and the sum cbonsisted of the first pair of the friendly numbers $(220+284=504) \ldots$... (Rakočević, 1997b, Fig. 7, p. 60) www.rakocevcode.rs [The unity of chemism and semiosis (VI)]

In the further course of this synopsis, come ilustrations in support of the main conclusion that will follow in the regular work. And the conclusion is: That what makes the genetic code, as a code, is the unity of unique mathematical forms and unique chemical essences; of unique forms as signifiers and unique essences as signified. 


\section{Tables}

Table 1. "A specific protein amino acids arrangement" which follows from Display 4, from the right side [The unity of chemism and semiosis (VII)]

\begin{tabular}{|c|c|c|c|c|c|}
\hline \multicolumn{4}{|c|}{119} & & \\
\hline G 01 & N 08 & L 13 & M 11 & (33) & \multirow{3}{*}{120} \\
\hline A 04 & D 07 & K 15 & F 14 & (40) & \\
\hline V 10 & S 05 & R 17 & Y 15 & (47) & \\
\hline Р 08 & Т 08 & Q 11 & W 18 & (45) & \multirow{3}{*}{117} \\
\hline I 13 & C 05 & E 10 & H 11 & (39) & \\
\hline G 01 & N 08 & L 13 & M 11 & (33) & \\
\hline $24 / 13$ & $18 / 23$ & 40/39 & $37 / 43$ & $118 / 119$ & \\
\hline \multirow[t]{2}{*}{ (37) } & (41) & (79) & (80) & $117 / \mathbf{1 2 0}$ & \\
\hline & & 118 & & & \\
\hline
\end{tabular}

"A specific protein amino acids arrangement: The first row is repeated at the bottom, and thus one cyclic system is obtained. There are 117 atoms in two outer columns; at even positions 118, at odd 119; in two inner columns 120 atoms. On the other hand, in the lower half of the Table there are 117 atoms ones more; in the lower diagonally 'wrapped' area 118, and in the upper 119; in the upper half of Table 120 atoms. The repeated four AAs at the bottom of the Table make to achieve a diagonal balance with a difference of only one atom; moreover, to establish a sequence from the series of natural numbers: 117, 118, 119, 120" (MMR, 2017, Table 4, p. 13). [Note (6.10.2021): The relation given in Display 2, in the form $(67+97=284-120) \rightarrow 384$, comes to full expression here: $220-100=\underline{\mathbf{1 2 0}} ; 220-101=\underline{\underline{\mathbf{1 1 9}}} ; 220-102=\underline{\mathbf{1 1 8}} ; 220-103=\underline{\mathbf{1 1 7}}$.] 
Table 2. The first specific protein amino acids arrangement which follows from Display 2 [The unity of chemism and semiosis (VIII)]

\begin{tabular}{|c|c|c|c|c|c|}
\hline \multicolumn{4}{|c|}{220} & & \\
\hline${ }_{01} G 10$ & $02 \mathrm{~A} 13$ & ${ }_{11} \mathrm{~N} 17$ & ${ }_{12}$ D 16 & (56) & \multirow{3}{*}{201} \\
\hline${ }_{03} \mathrm{~V} 19$ & ${ }_{04} \mathrm{P} 17$ & ${ }_{13} \mathrm{~S} 14$ & $\mathbf{1 4}$ T 17 & (67) & \\
\hline${ }_{05} \mathrm{I} 22$ & ${ }_{06} \mathrm{~L} 22$ & ${ }_{15} \mathrm{C} 14$ & ${ }_{16} \mathrm{M} 20$ & (78) & \\
\hline${ }_{07} \mathrm{~K} 24$ & ${ }_{08} \mathrm{R} 26$ & ${ }_{17} \mathrm{~F} 23$ & $18 \mathrm{Y} 24$ & (97) & \multirow{3}{*}{239} \\
\hline${ }_{09} Q 20$ & ${ }_{10}$ E 19 & ${ }_{19} \mathrm{~W} 27$ & ${ }_{20} \mathrm{H} 20$ & (86) & \\
\hline $01 \mathrm{G} 10$ & 02A 13 & ${ }_{11} \mathrm{~N} 17$ & ${ }_{12} \mathrm{D} 16$ & (56) & \\
\hline $52 / 53$ & $54 / 56$ & $\mathbf{5 8} / 54$ & $56 / 57$ & $220 / 220$ & \\
\hline (105) & (110) & (112) & (113) & $218 / 222$ & \\
\hline & & & & & \\
\hline
\end{tabular}

The amino acid Glutamine (Q) appears as the determinant of chemical distinction; from chemism because it is the only one complex amide in the set of 20 canonical amino acids; from semiosis because it is in the position of the golden mean on the 6-bit binary tree (MMR, 1998, Tab. 2, p. 288). The distinction through the operation $220-20=200(200+1=201)$ and $220+20=240$ $(240-1=239)$. 
Table 3. The second specific protein amino acids arrangement which follows from Display 2 [The unity of chemism and semiosis (IX)]

\begin{tabular}{|c|c|c|c|c|c|c|}
\hline \multicolumn{4}{|c|}{205} & & & \\
\hline $01 \mathrm{G} 10$ & $02 \mathrm{~A} 13$ & ${ }_{11} \mathrm{~N} 17$ & ${ }_{12}$ D 16 & (56) & \multirow{3}{*}{201} & \multirow{3}{*}{$\begin{array}{c}205 \\
239 \\
\downarrow \\
445-1\end{array}$} \\
\hline${ }_{03} \mathrm{~V} 19$ & ${ }_{04} \mathrm{P} 17$ & 13S 14 & $\mathbf{1 4}$ T 17 & (67) & & \\
\hline $05 \mathrm{I} 22$ & ${ }_{06} \mathrm{~L} 22$ & ${ }_{15} \mathrm{C} 14$ & ${ }_{16}$ M 20 & (78) & & \\
\hline${ }_{07} \mathrm{~K} 24$ & ${ }_{08} \mathrm{R} 26$ & ${ }_{17} \mathrm{~F} 23$ & $18 \mathrm{Y} 24$ & (97) & \multirow{3}{*}{239} & \multirow{6}{*}{$\begin{array}{c}235 \\
201 \\
\downarrow \\
445+1\end{array}$} \\
\hline${ }_{09} Q 20$ & ${ }_{10} \mathrm{E} 19$ & $19 \mathrm{~W} 27$ & $20 \mathrm{H} 20$ & (86) & & \\
\hline${ }_{01} \mathrm{G} 10$ & 02A 13 & ${ }_{11} \mathrm{~N} 17$ & ${ }_{12} \mathrm{D} 16$ & (56) & & \\
\hline $52 / 53$ & $\mathbf{5 4} / 56$ & $\mathbf{5 8} / 54$ & $56 / 57$ & $220 / \mathbf{2 2 0}$ & & \\
\hline (105) & (110) & (112) & (113) & $218 / 222$ & & \\
\hline \multicolumn{2}{|c|}{ (215) } & & & & & \\
\hline
\end{tabular}

The amino acid Histidine $(\mathrm{H})$ appears as the determinant of chemical distinction; from chemism because it is the least similar to glycine in the set of 20 canonical amino acids; from semiosis because it is the last amino acid in the set of 20 canonical amino acids. The distinction through the operation $205-20=185$ and $235+20=0255$. [Compare with the uniqueness that is given in the next Table 3.1.]

Table 3.1. The unique quantities in the set of natural numbers (shaded) found in GC arrangement in Table 3

[The unity of chemism and semiosis $(\mathrm{X})$ ]

\begin{tabular}{|c|c|c|c|c|}
\hline$(05 \times 49)$ & $=245$ & 195 & $=(15 \times 13)$ & \\
\hline$(05 \times 45)$ & $=225$ & 215 & $\approx(15 \times 14.3)$ & \\
\hline$(05 \times 41)$ & $=205$ & 235 & $\approx(15 \times 15.7)$ & \\
\hline (05 x 묵) & $=185$ & $\underline{\mathbf{0}} 255$ & $=(15 \times 17)$ & $16 \pm 1$ \\
\hline$(05 \times 33)$ & $=165$ & 275 & $\approx(15 \times 18.3)$ & \\
\hline$(05 \times 29$ & $=145$ & 295 & $\approx(15 \times 19.7)$ & \\
\hline
\end{tabular}

The number $\underline{\mathbf{0}} 255$ corresponds to the number $\underline{\mathbf{1}} 255$ through Schcherbak's hypothesis of "analogy with quantum physics" (Shcherbak, 1994). The number 1255 denotes the number of nucleons in 20 amino acid molecules (in their side chains). 
Table 4. Relations of ordinal number and number of atoms of amino acid molecules [The unity of chemism and semiosis (XI)]

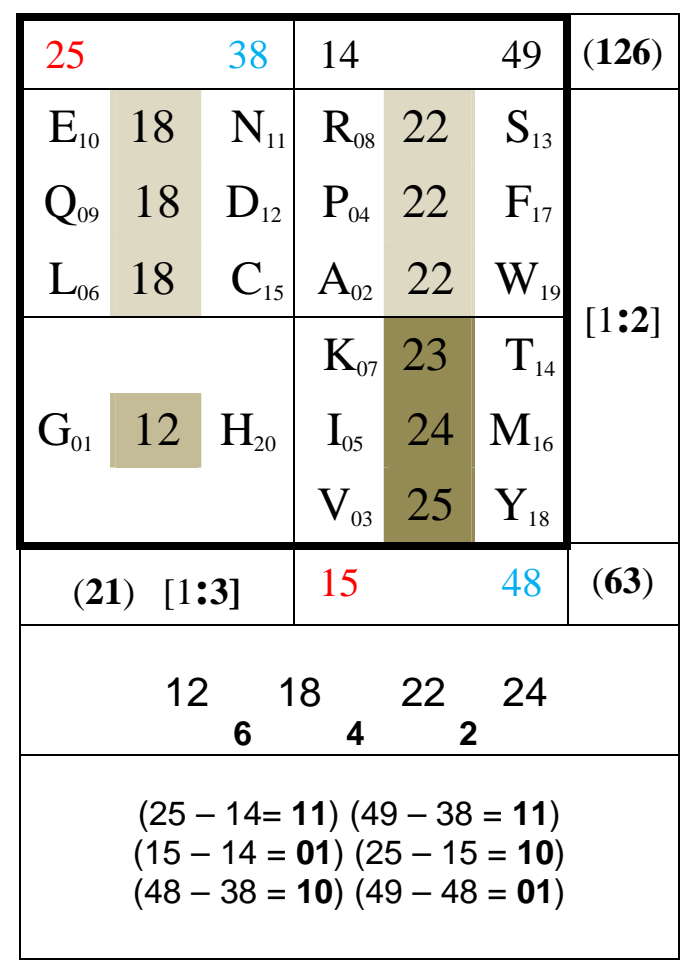

The result 12, 18, 22, 24 as unique result in the set of natural numbers "taken" from from Boolean spaces, as shown in Table 4.1. On the other hand, the quantities of 6, 4, 2 are found in another arrangement of the number of atoms in the genetic code, corresponding to the chemical code (MMR, 2018b, Tab. 4, p. 295). [See also Legend to Figure 4 in arXiv:2108.01563v4 [q-bio.BM] 
Table 4.1. The uniqueness of quantities 12, 18, 22, 24 in the set of natural numbers found in GC arrangement in Table 4 [The unity of chemism and semiosis (XII)]

\begin{tabular}{|lllllll|l|}
\hline$\ldots$ & & & & & & & \\
18 & 42 & 24 & 52 & 28 & 58 & 30 & $42+52=94(94-58=30+6)$ \\
16 & 38 & 22 & 48 & 26 & 54 & 28 & $38+48=86(86-54=28+4)$ \\
14 & 34 & 20 & 44 & 24 & 50 & 26 & $34+44=78(78-50=26+2)$ \\
$\mathbf{1 2}$ & $\mathbf{3 0}$ & $\mathbf{1 8}$ & $\mathbf{4 0}$ & $\mathbf{2 2}$ & $\mathbf{4 6}$ & $\mathbf{2 4}$ & $\mathbf{3 0}+\mathbf{4 0}=\mathbf{7 0}(\mathbf{7 0}-\mathbf{4 6}=\mathbf{2 4} \pm \mathbf{0})$ \\
10 & 26 & 16 & 36 & 20 & 42 & 22 & $26+36=62(62-42=22-2)$ \\
08 & 22 & 14 & 32 & 18 & 38 & 20 & $22+32=54(54-38=20-4)$ \\
06 & 18 & 12 & 28 & 16 & 34 & 18 & $18+28=46(46-34=18-6)$ \\
04 & 14 & 10 & 24 & 14 & 30 & 16 & $14+24=38(38-30=16-8)$ \\
02 & $\underline{\mathbf{1 0}}$ & 08 & 20 & 12 & 26 & 14 & $10+20=30(30-26=14-\underline{\mathbf{1 0}})$ \\
\hline
\end{tabular}

Table 4.2. The uniqueness of quantity 30 found in the shaded area of the previous Table 4.1.

\begin{tabular}{|c|c|c|c|}
\hline 12 & $8 \times 6$ & 12 & $6-2$ \\
\hline 38 & $+4=7 \times 6$ & 38 & $-4=2 \times 17$ \\
\hline 34 & $+2=6 \times 6$ & 34 & $-2=2 \times 16$ \\
\hline 30 & $-0=5 \times 6$ & 30 & $+0=$ \\
\hline 26 & $-2=4 \times 6$ & 26 & $+2=2 \times 14$ \\
\hline 22 & $-4=3 \times 6$ & 22 & $+4=2 \times 13$ \\
\hline 18 & $-6=2 \times 6$ & 18 & $+6=2 \times 12$ \\
\hline 14 & $-8=1 \times 6$ & 14 & $+8=2 \times 11$ \\
\hline 10 & $-10=0 \times 6$ & 10 & $+10=2 \times 10$ \\
\hline
\end{tabular}


Table 5. The uniqueness of 6-bit binary tree

\begin{tabular}{|c|c|c|c|}
\hline $2^{2}=4$ & $4^{1}=4$ & $2^{1}=2$ \\
$2^{4}=16$ & $4^{2}=16$ & $2^{3}=8$ \\
$2^{6}=64$ & $4^{3}=64$ & $2^{5}=32$ \\
$2^{8}=256$ & $4^{4}=256$ & $2^{7}=128$ \\
$2^{10}=1024$ & $4^{5}=1024$ & $\underline{2^{9}=512}$ \\
$\ldots$ & $8^{1}=8$ & $2^{3}=8$ \\
\hline \multicolumn{2}{|c|}{$(31 \times 16=496)(32 \times 16=512)$} \\
\hline $2^{2}=4$ & $8^{2}=64$ & $4^{3}=64$ \\
$2^{4}=16$ & $\underline{8^{3}=512}$ & $\underline{8^{3}=512}$ \\
$2^{6}=64$ & $8^{4}=4096$ & $16^{3}=4096$ \\
$2^{8}=256$ & $8^{5}=32768$ & $32^{3}=32768$ \\
$2^{10}=1024$ & $2^{2} \rightarrow(0-63) \rightarrow[101010]$ \\
$2^{9} \rightarrow(0-511) \rightarrow[101010101]$
\end{tabular}




\section{Appendix}

Table A1. The number of atoms in the Py-Pu bases and their corresponding nucleotides, determined by the first and second perfect numbers (I)

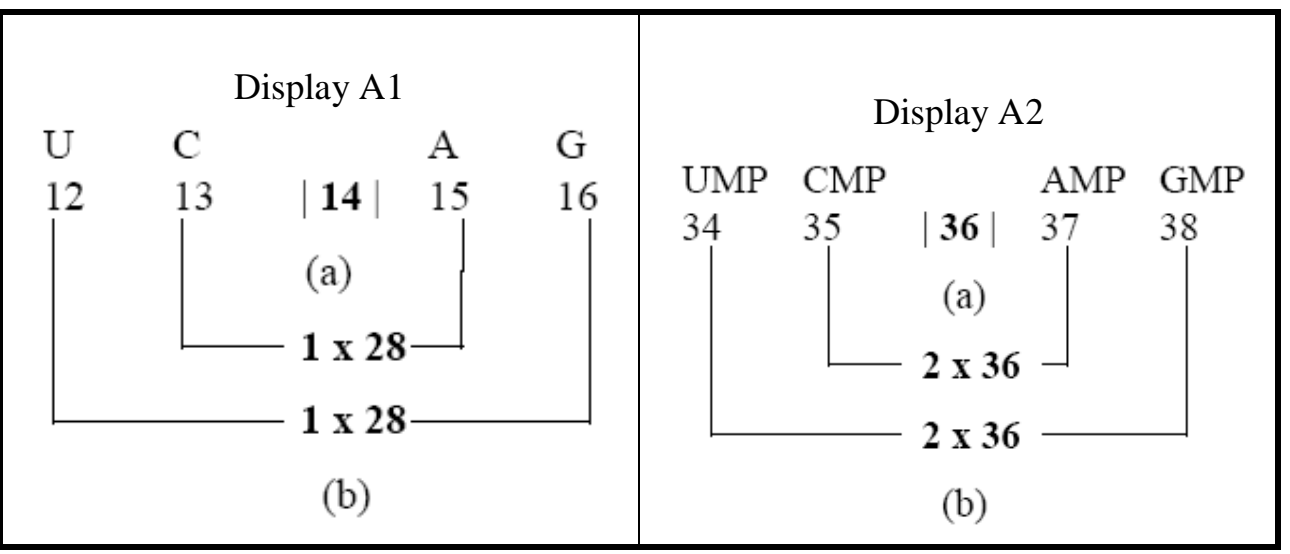

MMR, 1997b, Solution $25 \& 28$ pp. 62-63: "It should be noticed that the whole system is in a certain way determined by the first and second perfect number ... With this observation, however, it is easy to perceive that the total atom number within the four pu-pyr bases and their nucleotides is also determined by the relation of the first two perfect numbers (Solutions 25-29, pp. 62-63) ... In connection with this, non-existing entities (a) and yes-existing entities (b) exist in strict binary symmetry interrelations (cf. Solutions $25 \& 28$ with 29) [Here: Table A1 with Table A2 ..."] (Cf. Reference: MMR, 1997a.)

Table A2. The number of atoms in the Py-Pu bases and their corresponding nucleotides, determined by the first and second perfect numbers (II)

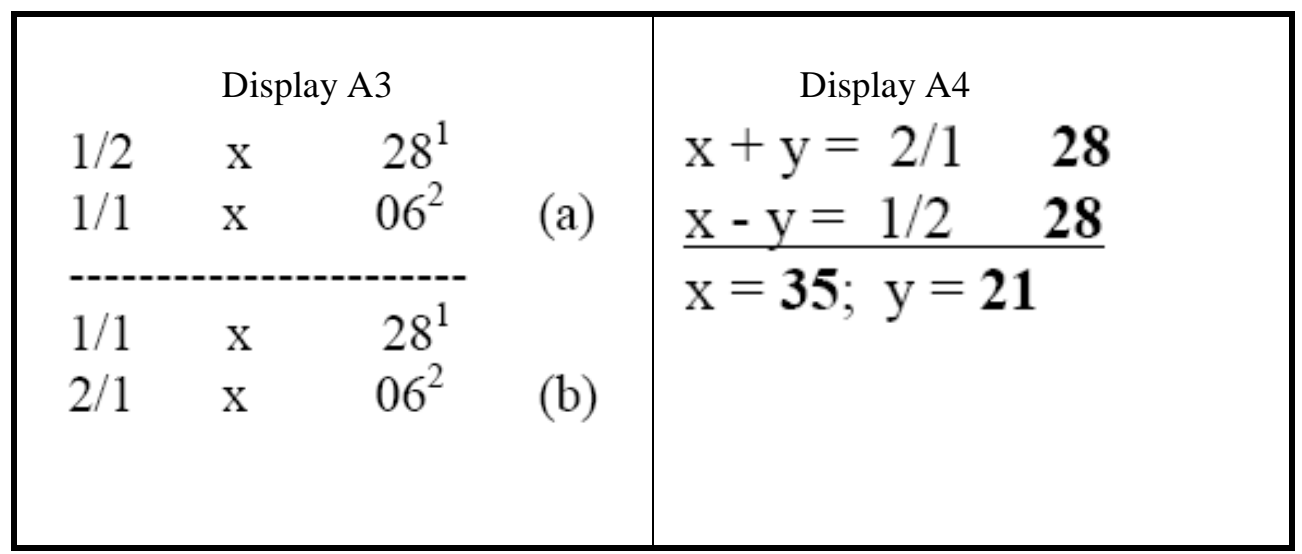


Table A3. The classification of protein (canonical) amino acids according to the essentiality in relation to Figure 1 and Table A2 (Display A4)

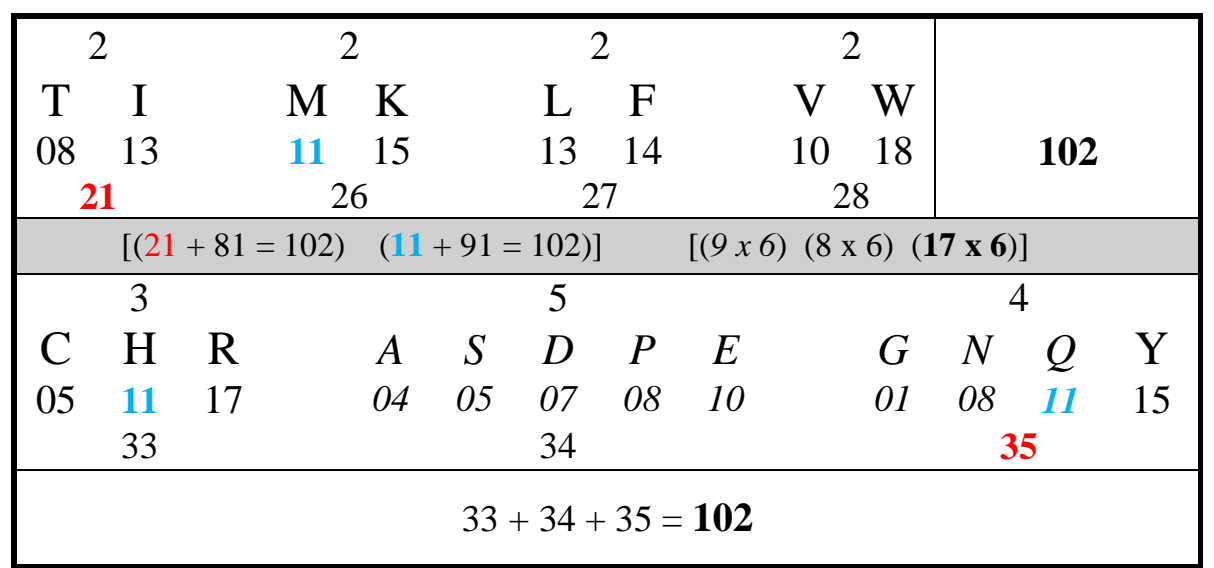

MMR, 1997b, Solution 29-2 \& 29-3, p. 63: "After our hypothesis ... not only the total pu-pyr atom number, but also the total amino acid atom number must be related to the first two perfect numbers in the next sense ... The amino acids [TIMKLFVW] are essential: first two (T, I) can make the diastereoisomers, the other cannot. The inner amino acids in [CHR ASDPEGNQ Y ] are nonessential, the outer semi essential. Notice that $34=06+28$ and that $27+33=26+34=10 \mathrm{x}$ 06. Notice also that atom number of 08 amino acids in [TIMKLFVW] is equal to the atom number of 12 amino acids in [CHR ASDPEGNQ Y]: $21+26+27+28=33+34+35=102 "$. [Note (6.10.2021): The classification is characterized by order of quantities of number of molecules and number of atoms. By this the quantities of first and last group of molecules (21 and 35 ) are the same ones we find as determinants of the system-arrangements of Py-Pu bases and their nucleotides (Display 4). This fact shows that the unity of the chemism and semiosis is realized through the unity of the two components of the genetic code, of nucleotides and amino acids. On the other hand, since this unity is mediated by second perfect number (Display 4), it is only proof more that perfect numbers are indeed determinants of the genetic code.] 
Table A3.1. The first proof of the uniqueness of the system-arrangement in Table A3

\begin{tabular}{|l|l|l|}
\hline$\ldots$ & \\
\hline $\begin{array}{l}\mathrm{x}+\mathrm{y}=2 / 1(24) \\
\mathrm{x}-\mathrm{y}=1 / 2(24)\end{array}$ & $\begin{array}{l}18,23,24,25 \\
28,29,30\end{array}$ & $\begin{array}{l}(87+3) \\
(87)\end{array}$ \\
\hline $\mathrm{x}=30 ; \mathrm{y}=18$ & & \\
$\mathrm{x}+\mathrm{y}=2 / 1(28)$ & $21,26,27,28$ & $(102 \pm 0)$ \\
$\mathrm{x}-\mathrm{y}=1 / 2(28)$ & $33,34,35$ & $(102)$ \\
\hline $\mathrm{x}=35 ; \mathrm{y}=21$ & & \\
\hline $\mathrm{x}+\mathrm{y}=2 / 1(32)$ & $24,29,30,31$ & $(117-3)$ \\
$\mathrm{x}-\mathrm{y}=1 / 2(32)$ & $38,39,40$ & $(117)$ \\
\hline $\mathrm{x}=40 ; \mathrm{y}=24$ & & \\
\hline$\ldots$ & & \\
\hline
\end{tabular}


Table A4. The second proof of the uniqueness of the system-arrangement in Table A3

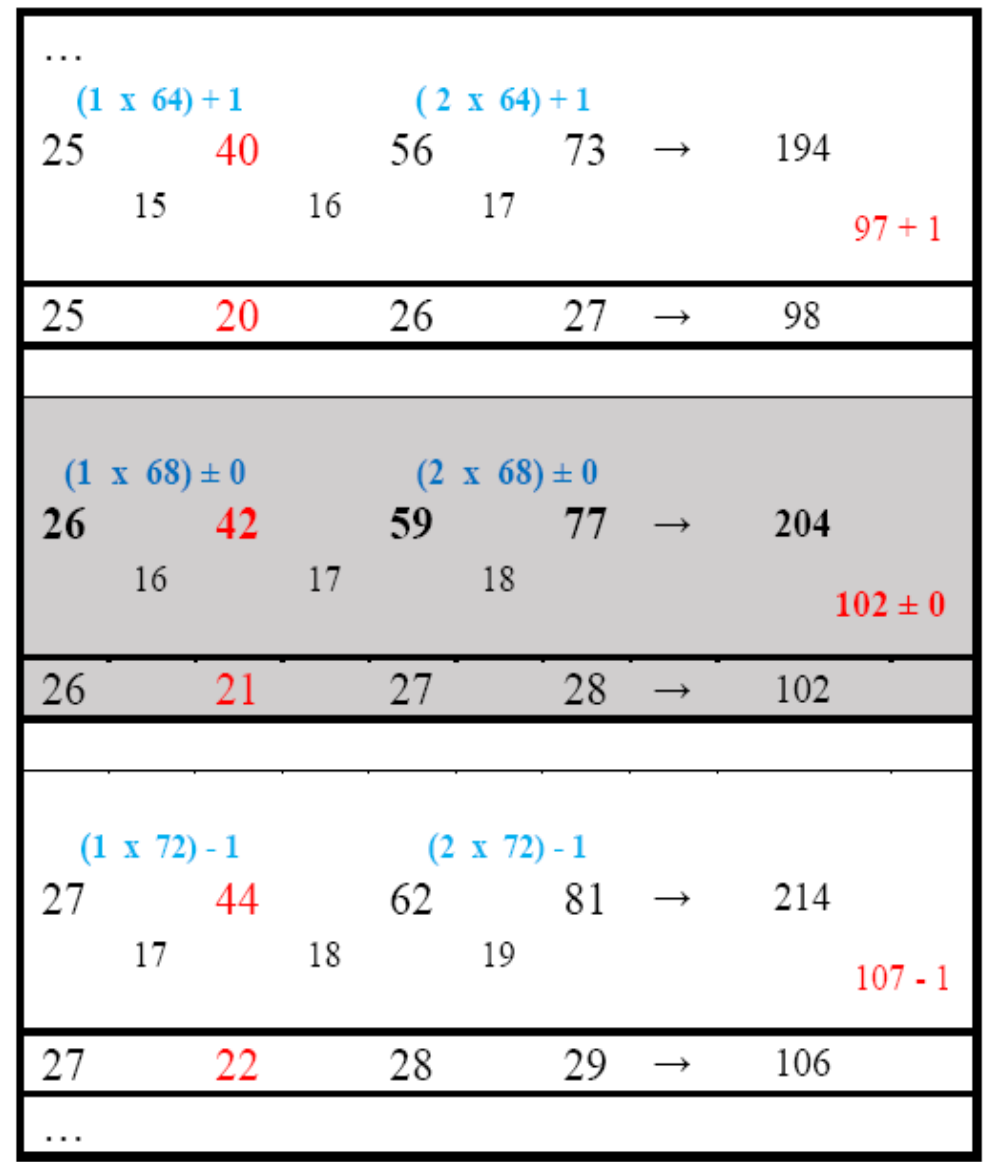


Table A4.1. The expansion of Table A4 one step up and one step down

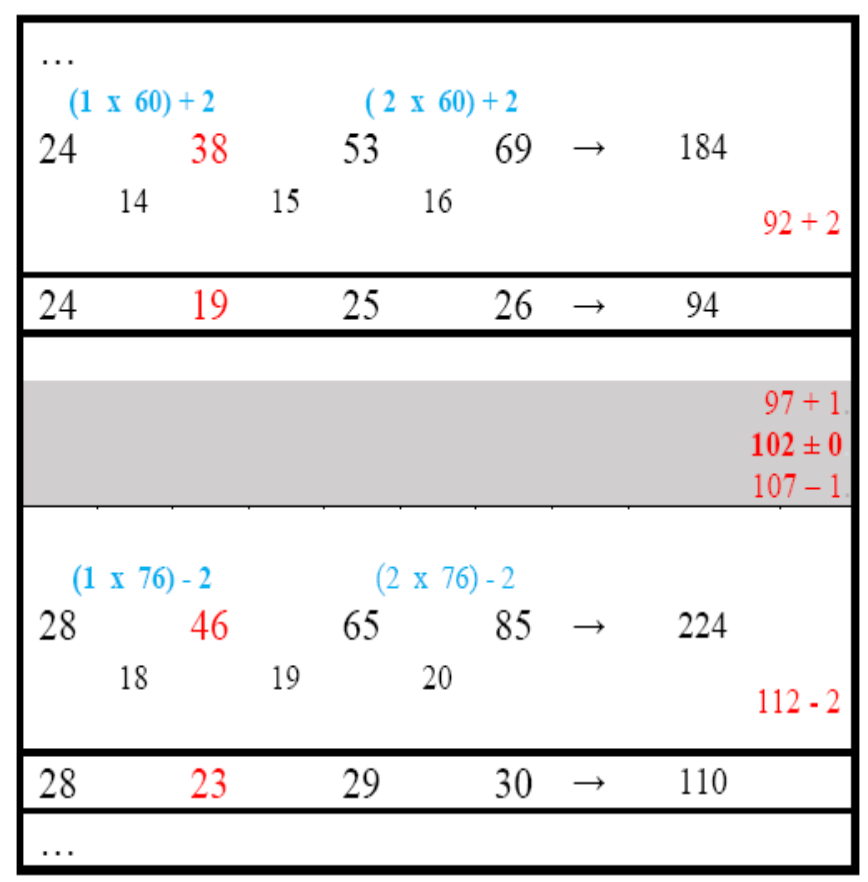

Table A5. The third proof of the uniqueness of the system-arrangement in Table A3

\begin{tabular}{|c|c|c|c|c|c|c|}
\hline G 01 & S 05 & $Y 15$ & W 18 & 39 & \multirow{2}{*}{78} & \multirow{3}{*}{102} \\
\hline A 04 & D 07 & M 11 & $\mathrm{R} 17$ & 39 & & \\
\hline \multirow{2}{*}{ C 05} & \multirow{2}{*}{ Т 08} & \multirow{2}{*}{ E 10} & \multirow{2}{*}{ F 14} & \multirow{2}{*}{37} & 24 & \\
\hline & & & & & \begin{tabular}{|l|}
13 \\
\end{tabular} & \multirow{2}{*}{102} \\
\hline N 08 & Q 11 & V 10 & | 13 & 42 & 89 & \\
\hline P 08 & H 11 & L 13 & K 15 & 47 & & \\
\hline 26 & 42 & 59 & 77 & & & \\
\hline & $\begin{array}{l}16 \\
1 \times 68)\end{array}$ & 17 & $\begin{array}{c}18 \\
2 \times 68)\end{array}$ & & & \\
\hline
\end{tabular}

MMR, 2011, Fig. 3, p. 828: "A specific classification and systematization of amino acids which follow from four diversity types ..." 


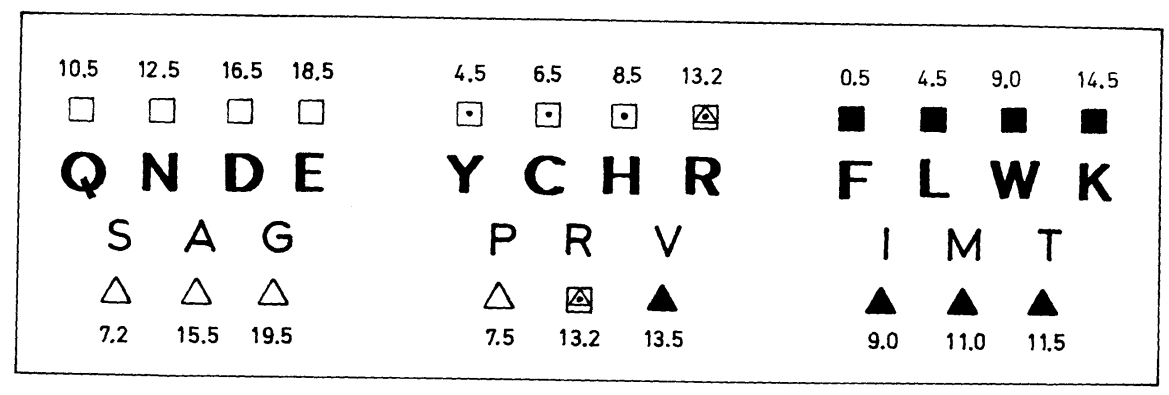

Figure A1. "Here are given the amino acids from Space-3 (triangles) and Space-4 (squares) depending on the binary value (strict order per rising values in each group) ...The mean binary values are given in Figure according to Rakočević, 1990, p. 10-11; 1994, p. 72. Note that the sequences $(\mathrm{Q}, \mathrm{N}, \mathrm{D}, \mathrm{E})$ and $(\mathrm{S}, \mathrm{A}, \mathrm{G}, \mathrm{P})$ are the same as in Mutation ring [in Fig. A2 and A3]." (MMR, 1997b, Figure 5, pp. 26-27.) [Note 1 (6. 10. 2021): Boolean Space-3 in Boolean cube, $\mathrm{B}^{3}$, corresponding with 6-bit binary tree (Table 5 in this Synopsis): 011-001, 011-010, 011-111; Space-4: 100-000, 100-101, 100-110.] [Note 2: As signified entities amino acid molecules appear here; and as signifiers appear Boolean spaces-3 and Boolean spaces-4, also the binary value of each of the molecules. The essentiality, however, appears in both roles.] [Note 3: The classification of amino acids into essential, semi-essential ("quasi-essential") and non-essential, as in (Van Nostrand, 1983, p. 119, Table 2).]

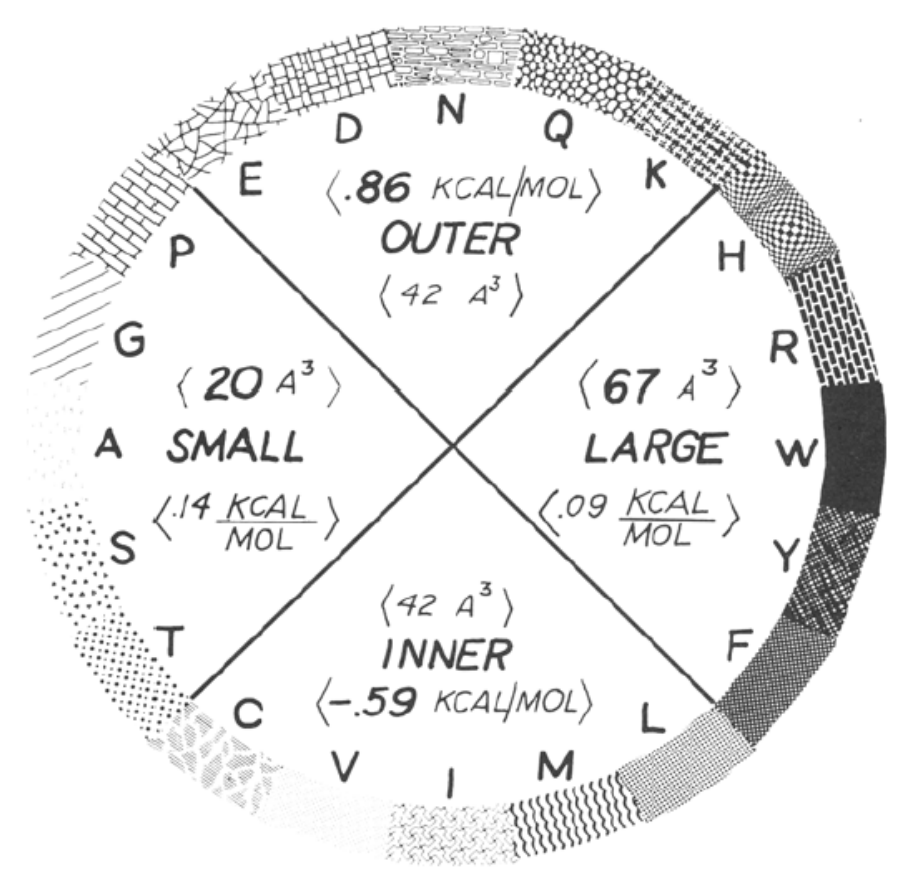

Figure A2. "Mutation ring. As the codon ring expresses the minimum change relation among codons, so the mutation ring expresses the minimum change relation among the amino acids. ..." (Swanson, 1984, Fig. 2, p. 191). 


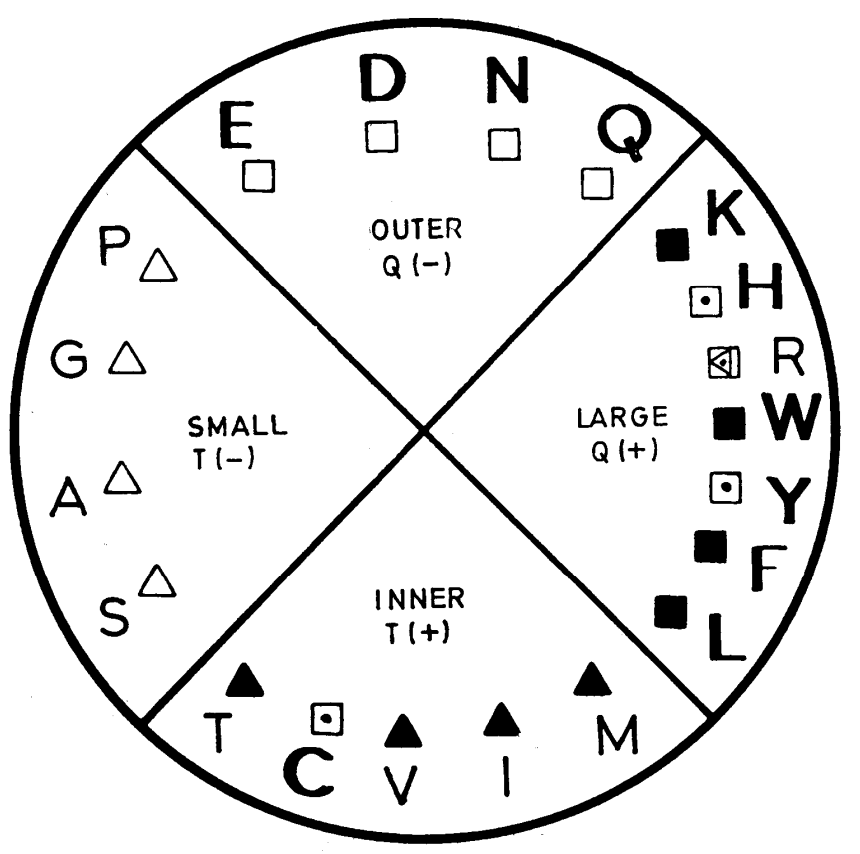

Figure A3. "Mutation ring II. This Ring could be regarded the Mutation ring II provided that R. Swanson's Mutation Ring (Swanson, 1984, Fig. 2) is regarded the Mutation Ring I; Everything is the same as on Mutation Ring I, only the ST-QK line is shifted by one step on both ends in relation to Mutation Ring I; and PE-ML line is shifted only on one (the other) end. The squares designate the amino acids from Space- 4 and triangles designate the amino acids from Space- 3 . The empty squares and empty triangles designate the nonessential amino acids, otherwise they designate the essential amino acids; the dots designate the semi-essential amino acids. The lines strictly separate non-essential from yes-essential amino acids; then the lines strictly separate the Space- 3 amino acids from Space-4 amino acids. There are the two exceptions: $\mathrm{C}$ is full-strayed; $\mathrm{R}$ is semi-strayed. One should note that the complementarity principle is applied as follows: outerinner: non-essential amino acids from Space-4 are complementary with the essential amino acids from Space-3, etc." (MMR, 1997b, Fig. 6, p. 28). [Note (6. 10. 2021): As signified entities amino acid molecules appear here; and as signifiers appear Boolean spaces-3 and Boolean spaces- 4 . The essentiality, however, appears in both roles.] 


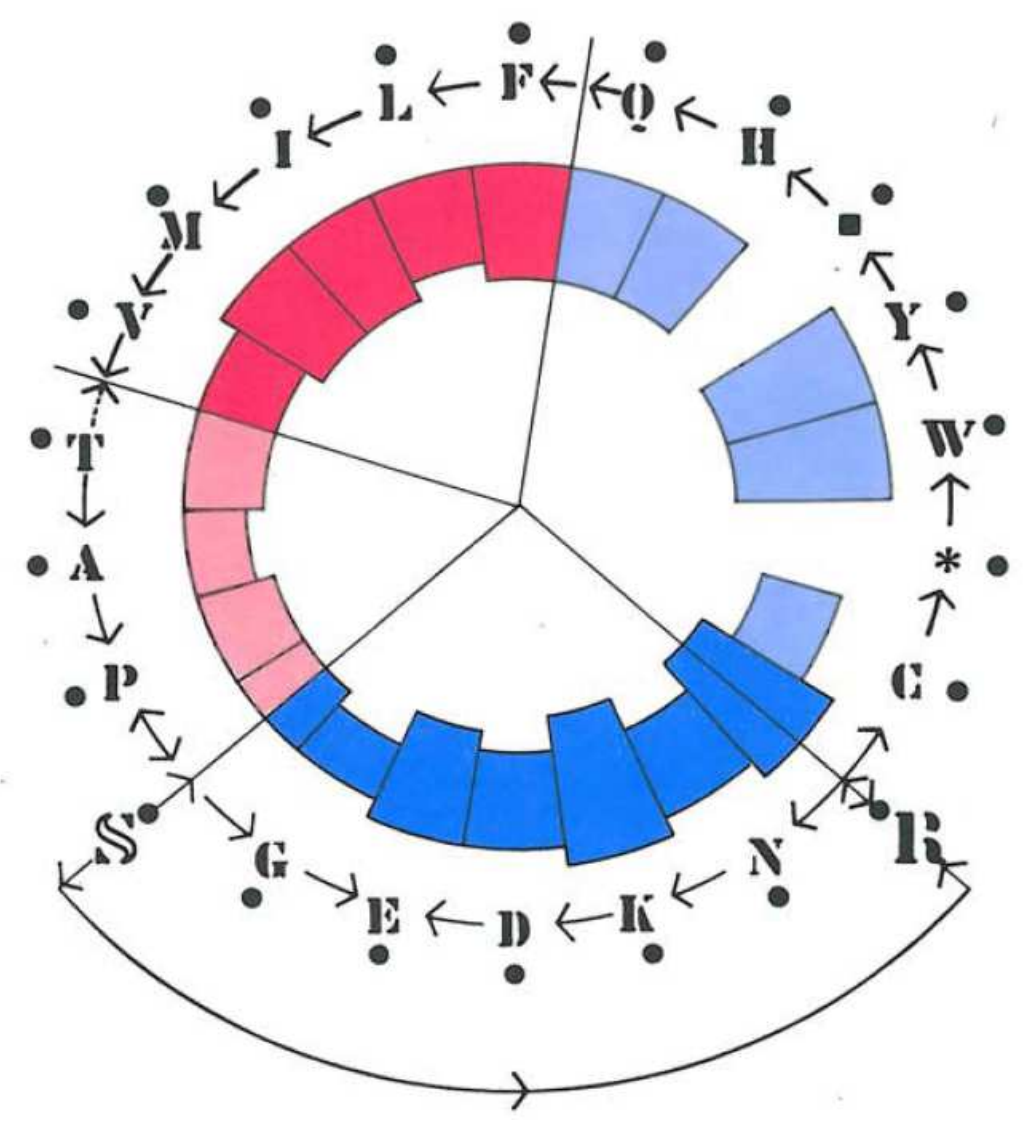

Figure A4. MMR, 1988, Fig. 30 as well as Fig. 34, p. 117 and 129) (text in Section 4, on p. 183): "The amino acid ring shows a marked division into two groups: hydrophobic, on the left side of the ring, and hydrophilic, on the right side. The first amino acids are coded by pyrimidine as the middle base, and the second by purine. Such a division ... is justified by the experimental measuring of hydropathy (Kyte and Doolitlle, 1982) and polarity (Woese, 1966)". [Note (6. 10. 2021): I came to the hypotheses that are the subject of this synopsis at the time when I wrote the book from which this illustration is taken, so 33 years ago. However, I could not disclose them publicly because I did not have reliable facts. The facts about the mirror symmetry, presented in the Box 1, encouraged me to do that now.] 


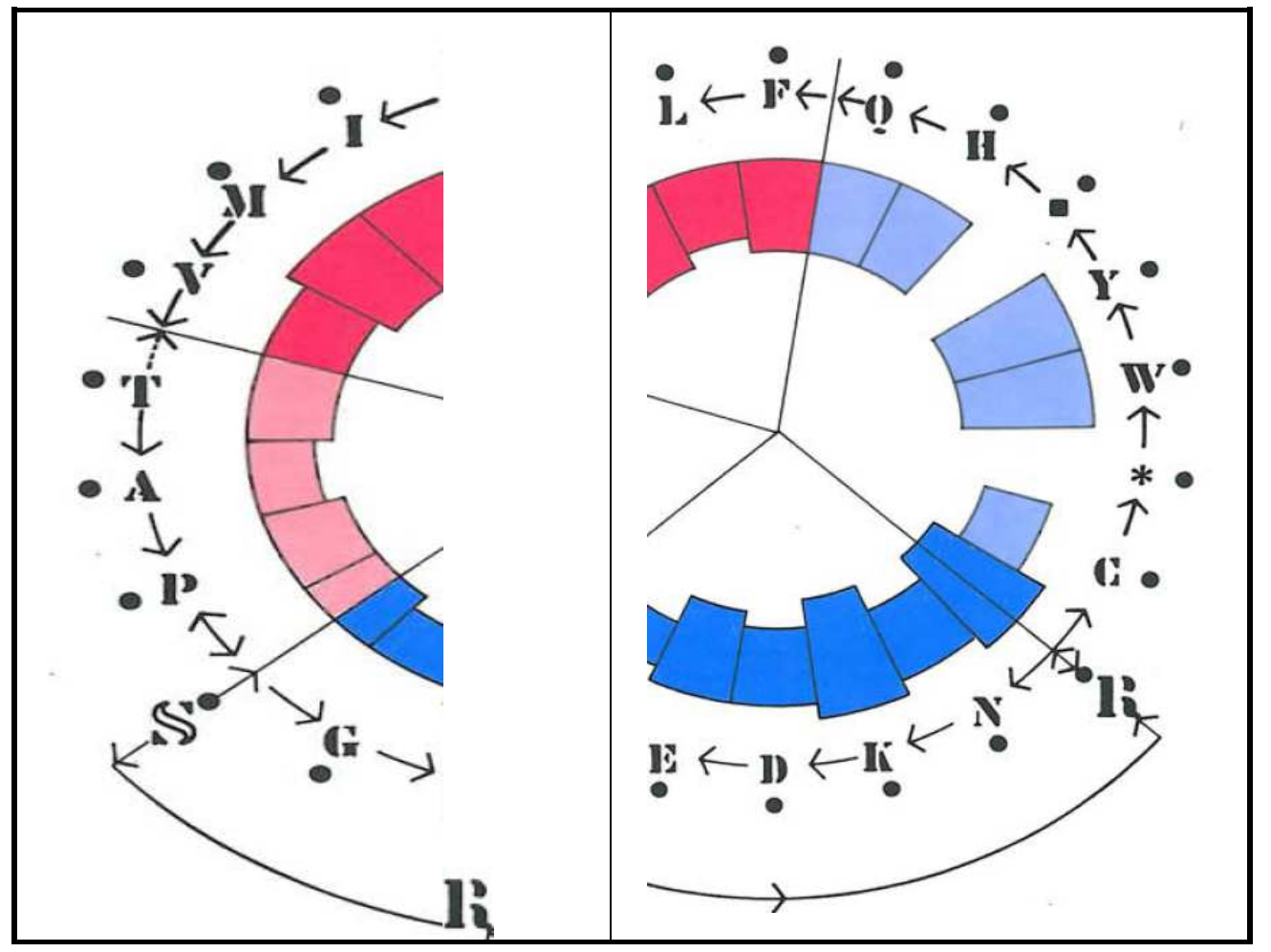

Figure A4.1. The splitting of the amino acid ring from the previous Figure into two parts: on the left is the Boolean space-3 and on the right The Boolean space-4, from the aspect of the positions of which amino acids they have on the 6-bit binary tree (MMR, 1998, Fig. 1, p. 284). 


\section{References}

De Saussure, F., 1985. Cours de linguistique générale, Payot, Paris.

Kyte, J., Doolittle, R.F., 1982. A simple method for displaying the hydropathic character of a protein. J. Mol. Biol. 157, 105-132.

Marcus, S., 1989. The symmetry in the Simplest Case: The Real Line. Computers Math. Applic. $17,103-115$.

Rakočević, M.M., 1994. Logic of the Genetic Code, Naučna knjiga, Beograd. www.rakocevcode.rs)

Rakočević, M.M., 1997a. Two classes of the aminoacyl-tRNA synthetases in correspondence with the Codon path cube, Bull. Math. Biol. Vol. 59, No. 4, pp. 645-648.

Rakočević, M.M., 1997b. Genetic Code as a Unique System, Studentski kulturni centar, Niš. http://www.rakocevcode.rs

Rakočević, M.M., 1998. The genetic code as a Golden mean determined system, Biosystems, 46, 283-291.

Rakočević, M.M., 2004. A harmonic structure of the genetic code. J. Theor. Biol. 229, 221-234.

Rakočević, M.M., 2011. Genetic code as a coherent system, NeuroQuantology, 9 (4), 821-841. http://www.rakocevcode.rs

Rakočević, M.M., 2017. Genetic code: Chemical distinctions of protein amino acids. OSF Preprints, DOI 10.31219/osf.io/86rit

Rakočević, M.M., 2018a. The Cipher of the Genetic Code, BioSystems 171 (2018) 31-47.

Rakočević, M. M., 2018b. Analogies of Genetic and Chemical Code, Polyhedron, 153, 292-298.

Rakočević, M.M., 2019. Protein amino acids as a complete (periodic) system, Chemia Naissensis, Vol 2, Issue 1, pp. 1-43.

hhttps://www.pmf.ni.ac.rs/chemianaissensis/archives/volume-2-number-1-2019/.

Rakočević, M.M., 2021. System-directed pairing of protein amino acids, OSF Preprints (Part I: DOI 10.31219/osf.io/bpqzt and Part II:

Rumer, Yu. B., 1966. O sistematizacii kodonov v geneticheskom kode, Doklady. Akad. Nauk. SSSR 167, 1393-1394.

Shcherbak, V. I., 1994. Sixty-four Triplets and 20 Canonical Amino Acids of the Genetic Code: The Arithmetical Regularities. Part II. J. Theor. Biol. 166, 475-477.

Swanson, R., 1984. A unifying concept for the amino acid code. Bull. Math. Biol. 46, 187-207.

Van Nostrand (1983) Scientific Encyclopedia, 6th Ed., Van Nostrand Reinhold Company, New York, Cincinnati, Toronto, London, Melbourne.

Woese, C.R., et al., 1966. On the fundamental nature and evolution of the genetic code.

Cold Spring Harb. Symp. Quant. Biol. 31, 723-736. 